\title{
Integrasi Permodelan Game Content Model Pada Game Based Learning
}

\author{
Riska Nurtantyo Sarbini, Indah Yuni Astuti, Tri Handayani \\ Universitas Islam Kadiri
}

\begin{abstract}
Abstrak-Permainan digital menjadi salah satu inovasi yang terus menjadi pilihan yang memberikan pengalaman dan membuka wacana sesuai dari pesan yang ingin disampaikan oleh pembuat game tersebut. Secara implisit pesan tersebut secara tidak langsung memiliki pengaruh terhadap pemahaman pemain. Di dalam Game-Based Learning terdapat lingkungan pembelajaran berbasis permainan yang dapat menginspirasi siswa untuk belajar, dan memberikan para siswa kesempatan belajar yang besar untuk meningkatkan pembelajaran mereka. Salah satu alasan bahwa game berbasis pembelajaran memiliki sejumlah karakteristik yang melibatkan siswa dan menawarkan pengalaman belajar yang menyenangkan. Dipadukan dengan formalitas dalam pembuatan game agar membuat permainan semakin bagus.

Formalitas Game Content Model merupakan ontologi permainan dari sudut pandang konten interaktif. terdiri dari model yang mewakili aspek inti dari sebuah game yang serius termasuk definisi objek, atribut, perilaku, hubungan dengan seni dan komponen pustaka game, peristiwa dan perkembangan, pembangunan situasi yang terdiri dari karakter, objek, tujuan, peristiwa dan masalah yang harus diselesaikan melalui gameplaying.

Penelitian berfokus pada pengembangan media pembelajaran digital berupa game based learning dengan integrasi dengan game content model sebagai formalitas dalam pembuatan game agar memiliki lingkup permainan yang serius.
\end{abstract}

Kata Kunci-Game-Based Learning, Game Content Model.

\begin{abstract}
Digital games become one of the innovations that continue to be an option that provides experience and opens the appropriate discourse of the message to be conveyed by the game maker. Implicitly the message indirectly has an influence on the player's understanding. In Game-Based Learning there is a game-based learning environment that can inspire students to learn, and give students a great learning opportunity to improve their learning. One of the reasons that learning-based games have a number of characteristics that involve students and offers a fun learning experience. Combined with formality in game making to make the game even better.

Game Content Model Model is a game ontology from an interactive content point of view. consists of models representing the core aspects of a serious game including object definitions, attributes, behaviors, relationships with the arts and components of game libraries, events and developments, constructing situations consisting of characters, objects, objectives, events and problems to be solved through gameplaying.

Research focuses on developing digital learning media in the form of game based learning with integration with game content model as a formality in game making in order to have serious game scope.
\end{abstract}

Keywords—Game-Based Learning, Game Content Model.

\section{PENDAHULUAN}

Permainan digital menjadi salah satu inovasi yang terus menjadi pilihan yang memberikan pengalaman dan membuka wacana sesuai dari pesan yang ingin disampaikan oleh pembuat game tersebut. Secara implisit pesan tersebut secara tidak langsung memiliki pengaruh terhadap pemahaman pemain. Penelitian ini difokuskan untuk menyampaikan pesan tentang pemahaman 
nasionalisme dan bela negara secara implisit serta dikemas dalam sebuah permainan digital dengan konsep Game-Based Learning.

Di dalam Game-Based Learning terdapat lingkungan pembelajaran berbasis permainan yang dapat menginspirasi siswa untuk belajar, dan memberikan para siswa kesempatan belajar yang besar untuk meningkatkan pembelajaran mereka (Charles dkk, 2012). Salah satu alasan bahwa game berbasis pembelajaran memiliki sejumlah karakteristik yang melibatkan siswa dan menawarkan pengalaman belajar yang menyenangkan. Di satu sisi, Game-Based Learning melibatkan media interaktif bagi siswa untuk berpartisipasi didalamnya, yang mendukung tren pembelajar berpusat desain, dan cocok untuk media generasi baru siswa (Zhi Hong dkk, 2010). Dengan aturan yang berada pada permainan dan scenario yang sangat mendukung akan menjadi sangat cocok akan menjadi sangat bagus apabila game based learning dijalankan pada permainan dengan konsol role playing games.

Role Playing Game merupakan jenis game dimana pemain harus mengikuti alur cerita permainan agar bisa menyelesaikan permainan. Di dalam permainan terdapat alur cerita yang memang telah ditentukan, aspek yang menjadi perbedaan hasil akhir adalah dari segi tantangan agar dapat menyelesaikan misi-misi yang terdapat didalamnya. Setiap tantangan tersebut merupakan faktor utama untuk membuat game itu menjadi menarik. Tantangan yang menjadikan sebuah game menjadi atraktif karena mampu mempengaruhi komponen neurologis pemain (Ryan, 2011), merupakan tantangan yang berbasis kinerja ataupun Novelty yang mencari penghargaan sistem, perjudian, belanja, jenis kelamin, dan pesta makan. Dari segi tantangan Role Playing Game memiliki perbedaan dengan game lain dimana tantangan berasal dari alur cerita permainan bukan berasal dari kompetisi dengan pemain lain, sehingga pemain dituntut sebaik mungkin dapat mengembangkan karakter dengan baik agar dapat menyelesaikan tantangan dari alur cerita.

Game Content Model merupakan ontologi permainan dari sudut pandang konten interaktif. Hal ini digunakan untuk mendokumentasikan spesifikasi desain permainan komputer dan akan digunakan sebagai model utama untuk membangun model permainan lainnya dalam kerangka pembangunan model-driven game serius (Stephen dkk, 2013), mengajukan model konten game baru yang dapat membantu desainer game dokumen spesifikasi desain game (Stephen dkk, 2013). Game Content Model (GCM) terdiri dari model yang mewakili aspek inti dari sebuah game yang serius termasuk definisi objek, atribut, perilaku, hubungan dengan seni dan komponen pustaka game, peristiwa dan perkembangan, pembangunan situasi yang terdiri dari karakter, objek, tujuan, peristiwa dan masalah yang harus diselesaikan melalui gameplaying (Stephen dkk, 2010). Game Content Model meningkatkan kinerja yang ada dari Game Ontology Project (GOP) (Zagal dkk, 2005), Rapid Analisys Method (RAM)(Jarvinen, 2007) dan Narrative, Entertainment, Simulation and Interaction(NESI) Model (Sarinho dkk, 2008). Ada tingkat kesamaan dengan ketiga model ini dalam aspek definisi permainan, namun ketiga model tersebut kurang memiliki formalisme yang dibutuhkan untuk penerjemahan model dan tidak ada konsep yang penting dalam menggambarkan karakteristik permainan dari perspektif rekayasa perangkat lunak. Sehingga dengan GCM tersebut dapat membuat game-based learning menjadi lebih memiliki nilai formalitas didalamnya.

Berdasarkan deskripsi diatas dilakukan penelitian tentang pengembangan media pembelajaran digital berupa game based learning dengan integrasi dengan game content model sebagai formalitas dalam pembuatan game agar memiliki lingkup permainan yang serius.

\section{METODE PENELITIAN}

\section{a. Model Yang Digunakan}

Penelitian ini bertujuan untuk pembantu proses pembelajaran dengan melalui media game agar membuat pemain memahami konsep dengan sudut pandang yang berbeda khususnya dari segi permainan Role Playing Games. Poin kunci dan arsitektur sistem tergambar, seperti yang telihat pada Gambar 1. 


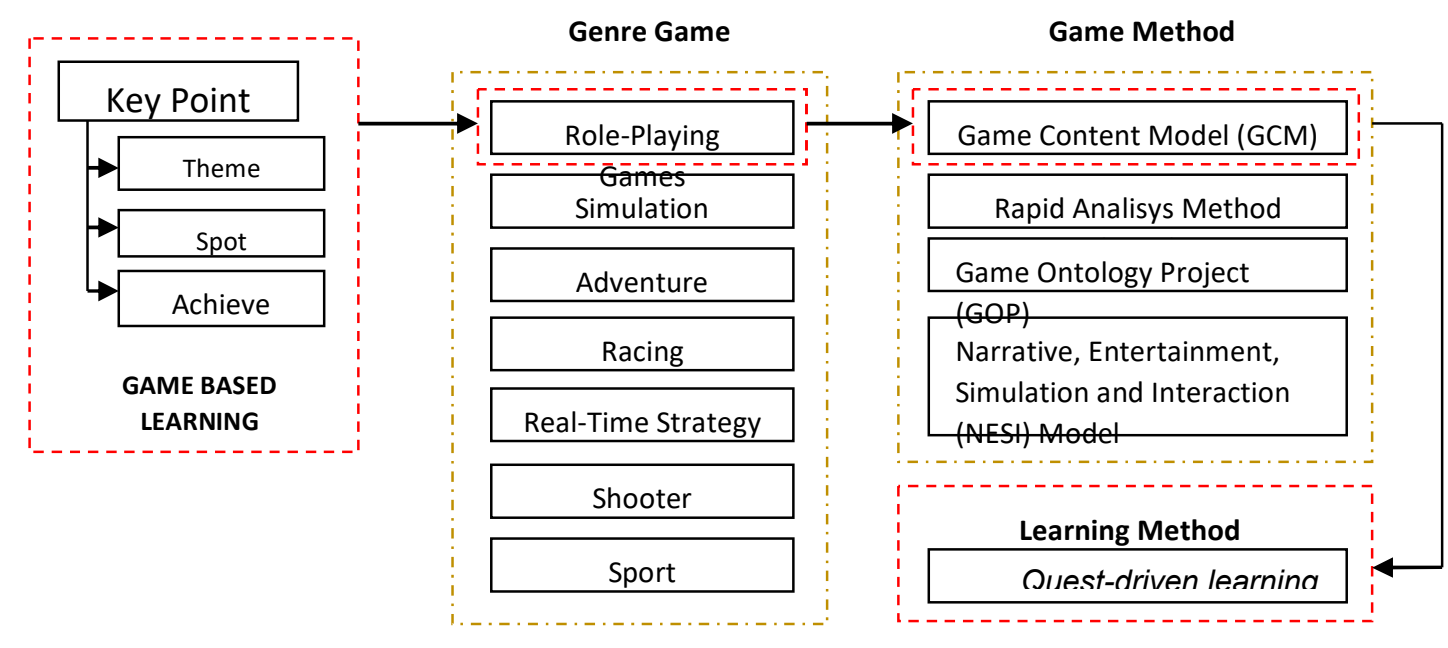

Gambar 1 Konsep Penelitian

\section{b. Game Content Model}

Game Content Model merupakan formalitas pembuatan game serius, dimaksudkan bahwa dapat memberikan solusi kepada para pemain dalam pembelajaran konsep model pembuatan sistem aplikasi game seperti permainan serius. Peran GCM terlihat dari tabel 1 berikut.

Tabel 1 Komponen Kunci GCM

\begin{tabular}{|c|c|c|c|}
\hline No & Konsep & Bagian & Isi \\
\hline \multirow[t]{3}{*}{1.} & \multirow[t]{3}{*}{ Game Structure } & Context & Role Playing Game. \\
\hline & & Event Pedagogic & Adanya event pembelajaran. \\
\hline & & Event Trigger & $\begin{array}{l}\text { pertanyaan-pertanyaan terkait } \\
\text { pembelajaran }\end{array}$ \\
\hline \multirow[t]{2}{*}{2.} & \multirow[t]{2}{*}{ Game Presentation } & Media Component & $\begin{array}{l}\text { teks naskah, grafis, suara dan video } \\
\text { interaktif. }\end{array}$ \\
\hline & & Gui Component & $\begin{array}{l}\text { Button, list-box, radio-button dan } \\
\text { menu. }\end{array}$ \\
\hline \multirow[t]{4}{*}{3.} & \multirow[t]{4}{*}{ Game Simulation } & Game Dimension & 2 Dimensi. \\
\hline & & Game Teтро & Real-time Game. \\
\hline & & Game Physics & Petualangan $R P G$. \\
\hline & & Front End Display & Minimal 1024 x 800 piksel. \\
\hline \multirow[t]{2}{*}{4.} & \multirow[t]{2}{*}{ Game Rules } & Game Scoring Rules & $\begin{array}{l}\text { Fokus Berdasarkan Reward dan } \\
\text { waktu penyelesaian. }\end{array}$ \\
\hline & & Game Interaction Rule & $\begin{array}{l}\text { berfokus pengembangan karakter, } \\
\text { interaksi dengan } N P C \text { (Non Playable } \\
\text { Character) dan penyelesaian quest } \\
\text { didalamnya. }\end{array}$ \\
\hline \multirow[t]{3}{*}{5.} & \multirow[t]{3}{*}{ Game Scenario } & Game Environtment & $\begin{array}{l}\text { pembuatan sebuah area yang dipenuhi } \\
\text { oleh } N P C \text { dimana karakter dapat } \\
\text { berhubungan, melakukan kegiatan } \\
\text { ekonomi jual beli dan mendapatkan } \\
\text { penjelasan tentang pertanyaan. }\end{array}$ \\
\hline & & Virtual Camera & $\begin{array}{l}\text { penggunaan gambar karakter yang } \\
\text { sedang dimainkan. }\end{array}$ \\
\hline & & Difficulty Indicator & $\begin{array}{l}\text { peningkatan tingkat kesulitan } \\
\text { tergantung tingkat tahap permainan } \\
\text { dan meningkat di setiap levelnya }\end{array}$ \\
\hline 6. & Event Game & Game Event & $\begin{array}{l}\text { implementasi mini game dengan } \\
\text { tantangan-tantangan yang berbeda }\end{array}$ \\
\hline
\end{tabular}




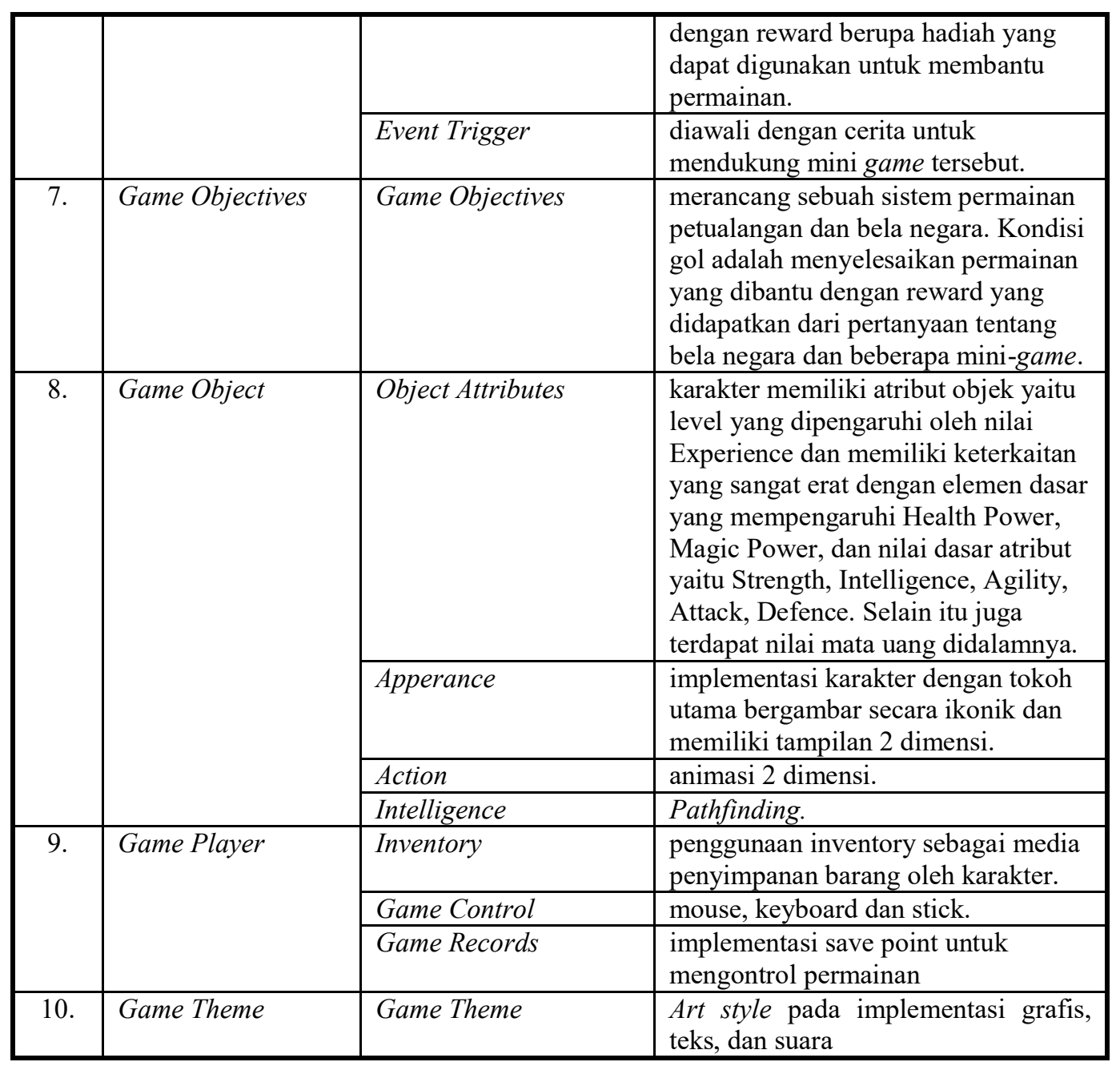

\section{INTEGRASI PERMAINAN}

\section{a. Role Playing Games}

RolePlaying Games merupakan permainan yang telah memiliki alur cerita dan pemain hanya mengembangkan karakter yang dapat memberikan pengalaman bermain dari sudut pandang cerita yang berbeda. Fokusnya adalah permainan selesai dengan secepat mungkin melalui tantangantantangan didalamnya terlihat dari tabel 2.2 .

Tabel 2 Topik Pembelajaran Dalam Permainan RPG

\begin{tabular}{|c|l|l|}
\hline No. & \multicolumn{1}{|c|}{ Topik } & \multicolumn{1}{|c|}{ Implementasi } \\
\hline 1. & $\begin{array}{l}\text { Pembelajaran Rambu Lalu-lintas dan } \\
\text { Perilaku }\end{array}$ & $\begin{array}{l}\text { - Pertanyaan-pertanyaan seputar } \\
\text { permainan }\end{array}$ \\
\hline 2. & Interaksi Sosial & - Interaksi Dengan NPC \\
\hline & & - Kegiatan Ekonomi \\
\hline & & - Quest \\
\hline 3. & Kedisiplinan Individu & $\begin{array}{l}\text { - Kegiatan Pribadi (Tidur, Makan, Mandi, } \\
\text { dsb) }\end{array}$ \\
\hline
\end{tabular}




\section{b. Quest Driven Learning}

Secara garis besar proses quest pada mekanisme Role-Playing mengacu pada pendekatan Quest-Driven Learning Model (Zhi Hong dkk, 2010) yang menerapkan konsep berupa reward untuk proses pembelajarannya.

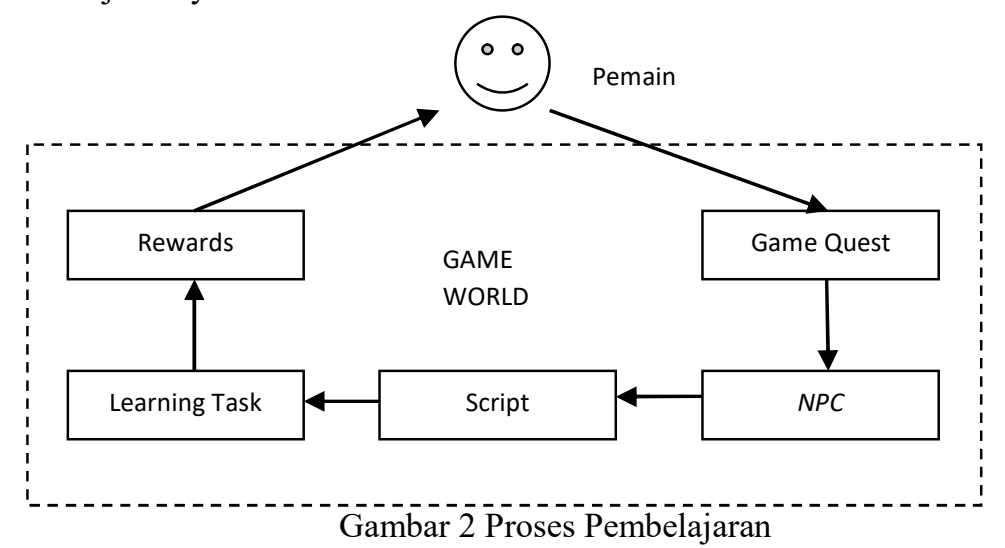

Dari gambar 2 pemain memiliki tingkat interaksi terhadap dunia permainan dimana didalamnya terdapat quest yang menjadi dasar dari proses pembelajaran. Pemicu dari quest berasal dari NPC yang terdapat di dalam dunia permainan dan NPC akan memberikan hadian sebagai tanda quest telah berhasil dilaksanakan. Hadiah tersebut digunakan untuk membantu pemain dalam menyelesaikan permainan.faktor yang luas dari tingkat pembuatannya, dengan menggunakan mekanisme Role Playing Games dengan komponen utamanya yaitu memiliki alur cerita yang sudah ditetapkan, dan pemain hanya mengembangkan kemampuan karakter, berinteraksi dengan sosial, melakukan kegiatan ekonomi. Salah satu faktor kunci yang dapat membantu dalam proses penyelesaian permainan dan harus dilalui adalah menjawab teka-teki tentang rambu-rambu lalu lintas sehingga memacu pemain untuk mencari pengetahuan dari interaksi dengan NPC maupun mencari bahan referensi dari sumber luar permainan. Diharapkan dalam setiap tahapan tantangan dapat dilewati dengan mudah, dengan tujuan memberikan pengalaman pembelajaran yang berbeda dalam mempelajari permainan. Metode Game Content Model memiliki faktor-faktor kunci yang harus dimiliki dalam sebuah game, sehingga diharapkan dapat digunakan untuk membantu perancangan pembuatan game secara formal. Urutan pemecahan masalah yang akan menjadi dasar permainan adalah seperti Gambar 3 dibawah ini: 


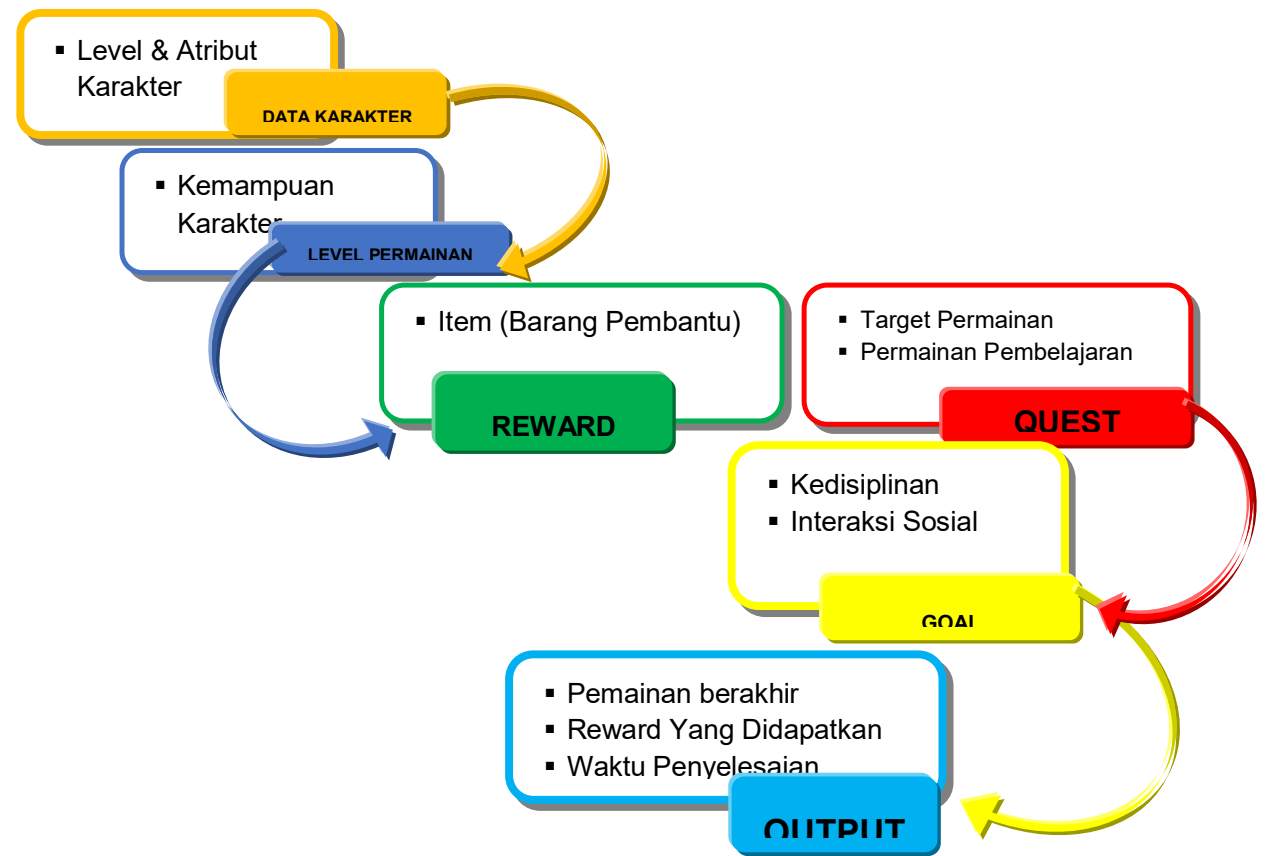

Gambar 3 Alur Sistem menggunakan Role Playing Games (Perancangan)

Berdasarkan Gambar 3 perancangan pertama dimulai dengan mendapatkan data karakter, berisi atribut dasar yang menentukan kemampuan karakter. Untuk proses penyelesaian permainan tergantung kepada kemampuan karakter agar dapat melewati level tersebut. Terkait konsep pada gambar 3, maka konsep salah satu quest dalam bentuk flow chart adalah seperti pada gambar 4 berikut.

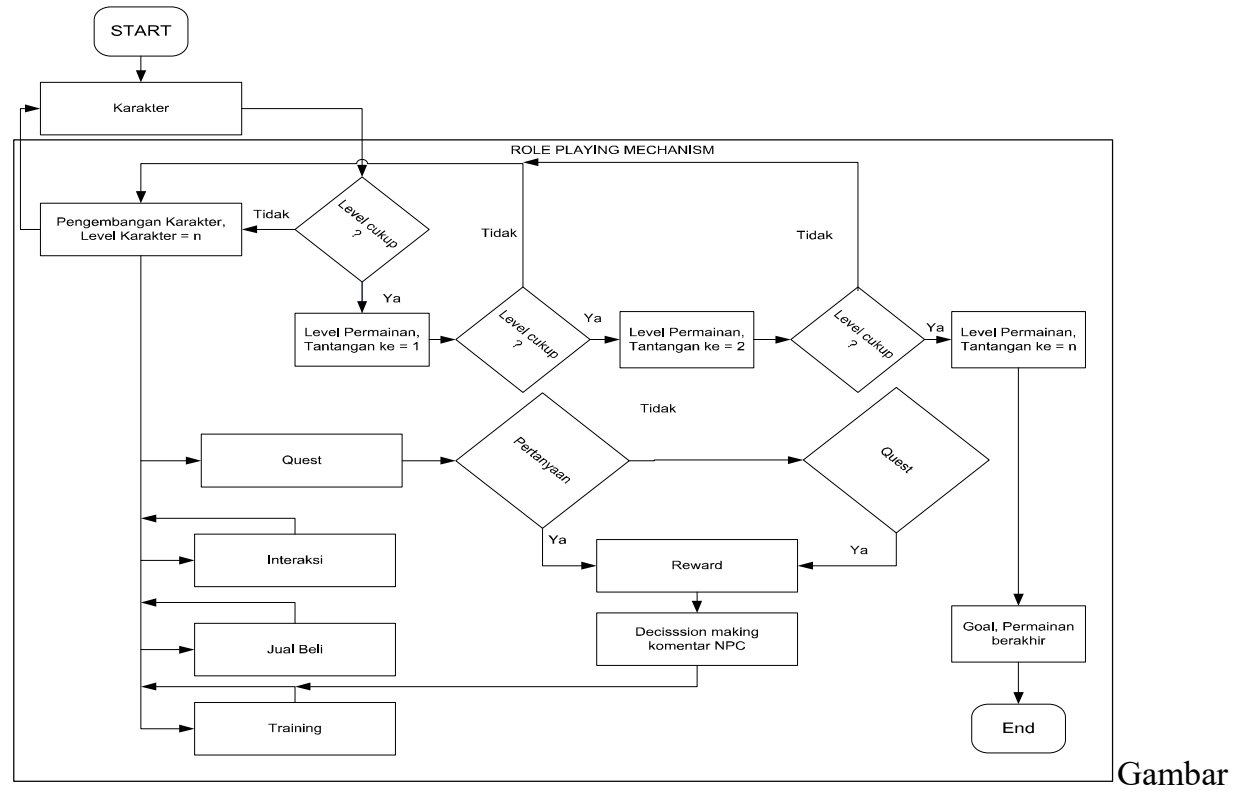

4 Flowchart Permainan

\section{HASIL DAN PEMBAHASAN}




\section{A. Interface Pengguna}

Tampilan antarmuka (User Interface) pengguna pada Game Pembelajaran. Bagian awal dari aplikasi adalah halaman index atau utama yang tampilannya seperti pada Gambar 5.

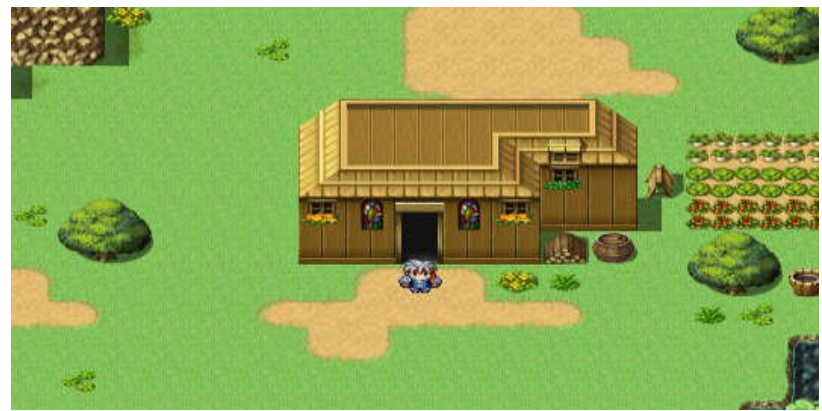

Gambar 5 Tampilan Halaman Form New Game

Selanjutnya adalah form untuk memperlihatkan peta utama dari keseluruhan permainan, terlihat terdapat kota-kota dan area dari keseluruhan permainan. Berikut tampilan peta keseluruhan pada Gambar 6.

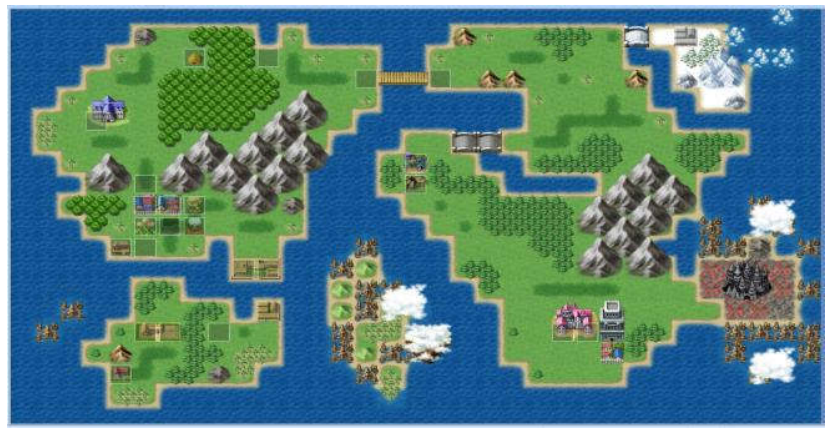

Gambar 6 Tampilan Halaman Peta Utama

Berikutnya adalah tampilan dari menu karakter. Dimana pemain dapat melihat isi item, perlengkapan, menyimpan permainan, mengatur formasi dan kembali ke menu utama, seperti pada Gambar 7.

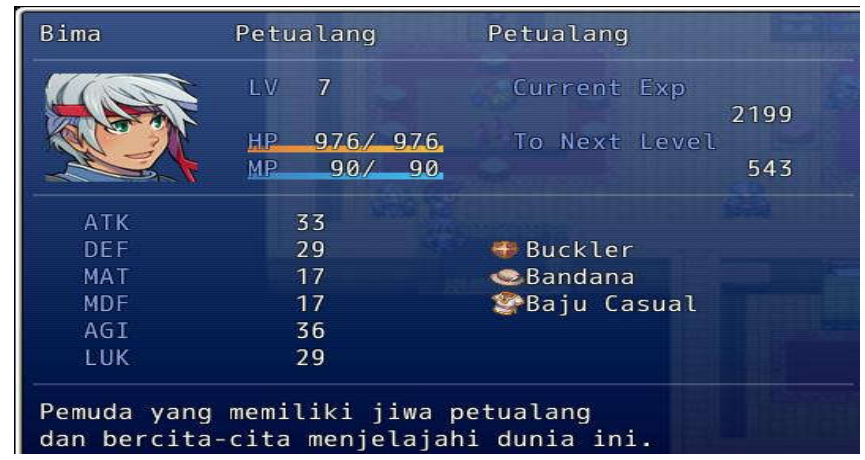

Gambar 7 Tampilan Halaman Data Karakter

B. Validasi GCM 
Proses validasi merupakan konfirmasi melalui pengujian dan penyediaan bukti objektif bahwa persyaratan tertentu untuk suatu tujuan khusus telah dipenuhi, sehingga dapat disimpulkan dari pembahasan diatas tingkat implementasi GCM telah berhasil diimplementasi, seperti pada tabel 3 berikut.

Tabel 3 Implementasi GCM Dalam Permainan

\begin{tabular}{|c|c|c|c|c|}
\hline No & Konsep & Bagian & Keterangan & Validasi \\
\hline \multirow[t]{3}{*}{1.} & \multirow{3}{*}{$\begin{array}{l}\text { Game } \\
\text { Structure }\end{array}$} & Context & Berhasil & Basis Permainan RPG. \\
\hline & & $\begin{array}{l}\text { Event } \\
\text { Pedagogic }\end{array}$ & Berhasil & Adanya event pembelajaran. \\
\hline & & Event Trigger & Berhasil & $\begin{array}{l}\text { pertanyaan-pertanyaan terkait } \\
\text { pembelajaran }\end{array}$ \\
\hline \multirow[t]{2}{*}{2.} & \multirow[t]{2}{*}{$\begin{array}{l}\text { Game } \\
\text { Presentation }\end{array}$} & $\begin{array}{l}\text { Media } \\
\text { Component }\end{array}$ & Berhasil & $\begin{array}{l}\text { Implementasi teks naskah, grafis, suara } \\
\text { dan video interaktif. }\end{array}$ \\
\hline & & Gui Component & Berhasil & $\begin{array}{l}\text { Implementasi Button, list-box, radio- } \\
\text { button dan menu. }\end{array}$ \\
\hline \multirow[t]{4}{*}{3.} & \multirow[t]{4}{*}{$\begin{array}{l}\text { Game } \\
\text { Simulation }\end{array}$} & $\begin{array}{l}\text { Game } \\
\text { Dimension }\end{array}$ & Berhasil & Tampilan 2 Dimensi. \\
\hline & & Game Tempo & Berhasil & Real-time Game. \\
\hline & & Game Physics & Berhasil & Petualangan RPG. \\
\hline & & $\begin{array}{l}\text { Front End } \\
\text { Display }\end{array}$ & Berhasil & Minimal 1024 x 800 piksel. \\
\hline \multirow[t]{2}{*}{4.} & \multirow[t]{2}{*}{ Game Rules } & $\begin{array}{l}\text { Game Scoring } \\
\text { Rules }\end{array}$ & Berhasil & $\begin{array}{l}\text { Fokus Berdasarkan Reward dan waktu } \\
\text { penyelesaian. }\end{array}$ \\
\hline & & $\begin{array}{l}\text { Game } \\
\text { Interaction Rule }\end{array}$ & Berhasil & $\begin{array}{l}\text { berfokus pengembangan karakter, } \\
\text { interaksi dengan NPC (Non Playable } \\
\text { Character) dan penyelesaian quest } \\
\text { didalamnya. }\end{array}$ \\
\hline \multirow[t]{3}{*}{5.} & \multirow[t]{3}{*}{$\begin{array}{l}\text { Game } \\
\text { Scenario }\end{array}$} & $\begin{array}{l}\text { Game } \\
\text { Environtment }\end{array}$ & Berhasil & $\begin{array}{l}\text { Implementasi sebuah area yang dipenuhi } \\
\text { oleh NPC dimana karakter dapat } \\
\text { berhubungan, melakukan kegiatan } \\
\text { ekonomi jual beli dan mendapatkan } \\
\text { penjelasan tentang pertanyaan. }\end{array}$ \\
\hline & & Virtual Camera & Berhasil & $\begin{array}{l}\text { penggunaan gambar karakter yang } \\
\text { sedang dimainkan. }\end{array}$ \\
\hline & & $\begin{array}{l}\text { Difficulty } \\
\text { Indicator }\end{array}$ & Berhasil & $\begin{array}{l}\text { peningkatan tingkat kesulitan tergantung } \\
\text { tingkat tahap permainan dan meningkat } \\
\text { di setiap levelnya }\end{array}$ \\
\hline \multirow[t]{2}{*}{6.} & \multirow[t]{2}{*}{$\begin{array}{l}\text { Event } \\
\text { Game }\end{array}$} & Game Event & Berhasil & $\begin{array}{l}\text { implementasi mini game dengan } \\
\text { tantangan-tantangan yang berbeda } \\
\text { dengan reward berupa hadiah yang dapat } \\
\text { digunakan untuk membantu permainan. }\end{array}$ \\
\hline & & Event Trigger & Berhasil & $\begin{array}{l}\text { diawali dengan cerita untuk mendukung } \\
\text { mini game tersebut. }\end{array}$ \\
\hline 7. & $\begin{array}{l}\text { Game } \\
\text { Objectives }\end{array}$ & $\begin{array}{l}\text { Game } \\
\text { Objectives }\end{array}$ & Berhasil & $\begin{array}{l}\text { merancang sebuah sistem permainan } \\
\text { petualangan dan pembelajaran. }\end{array}$ \\
\hline 8. & $\begin{array}{l}\text { Game } \\
\text { Object }\end{array}$ & $\begin{array}{l}\text { Object } \\
\text { Attributes }\end{array}$ & Berhasil & $\begin{array}{l}\text { karakter memiliki atribut objek yaitu } \\
\text { level yang dipengaruhi oleh nilai } \\
\text { Experience dan memiliki keterkaitan } \\
\text { yang sangat erat dengan elemen dasar } \\
\text { yang mempengaruhi Health Power, } \\
\text { Magic Power, dan nilai dasar atribut } \\
\text { yaitu Strength, Intelligence, Agility, } \\
\text { Attack, Defence. Selain itu juga terdapat } \\
\text { nilai mata uang didalamnya. }\end{array}$ \\
\hline
\end{tabular}




\begin{tabular}{|l|l|l|l|l|}
\hline & & Apperance & Berhasil & $\begin{array}{l}\text { implementasi karakter dengan tokoh } \\
\text { utama bergambar secara ikonik dan } \\
\text { memiliki tampilan 2 dimensi. }\end{array}$ \\
\cline { 3 - 5 } & & Action & Berhasil & animasi 2 dimensi. \\
\cline { 3 - 5 } & \multirow{2}{*}{\begin{tabular}{l} 
Player \\
\cline { 3 - 5 }
\end{tabular}} & Intelligence & Berhasil & Pathfinding. \\
\cline { 3 - 5 } & Game Control & Berhasil & $\begin{array}{l}\text { penggunaan inventory sebagai media } \\
\text { penyimpanan barang oleh karakter. }\end{array}$ \\
\cline { 3 - 5 } & Game Racords & Berhasil & $\begin{array}{l}\text { implementasi save point untuk } \\
\text { mengontrol permainan }\end{array}$ \\
\hline 10. & $\begin{array}{l}\text { Game } \\
\text { Theme }\end{array}$ & Game Theme & Berhasil & $\begin{array}{l}\text { Art style pada implementasi grafis, teks, } \\
\text { dan suara }\end{array}$ \\
\hline
\end{tabular}

\section{Analisis Hasil Kuisioner dan Pertanyaan Tentang Permainan}

Kuesioner adalah pertanyaan tertulis yang diberikan kepada responden untuk menjawab. Sebelumnya harus dipastikan kebenaran atas responden yang diteliti berdasarkan kriteria respondennya. Dari percobaan dan implementasi hasil desain, verifikasi dan validasi telah didapatkan beberapa hasil. Untuk menguji dan membuktikan hasil yang diperoleh dilakukan proses kuisioner dan pertanyaan seputar permainan terhadap 50 pemain.

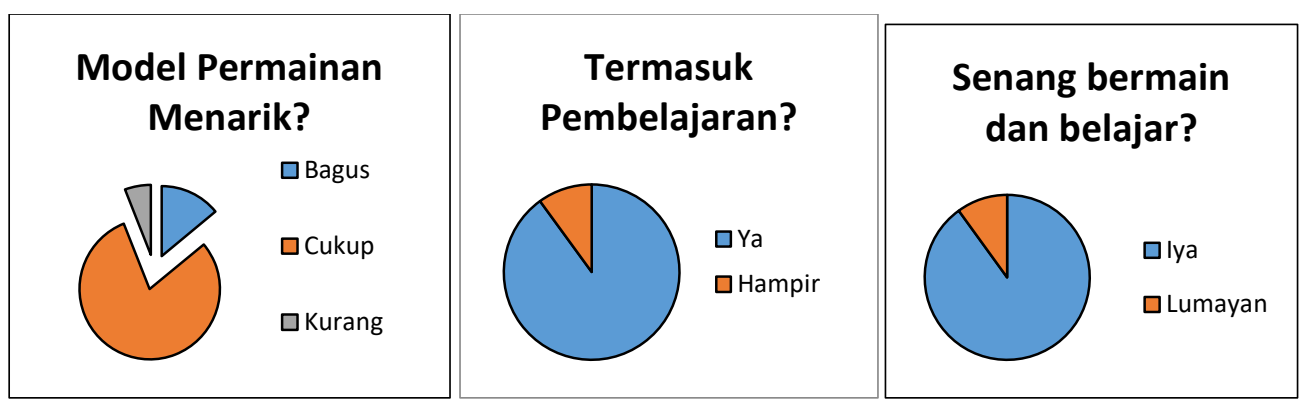

Gambar 8 Grafik Asumsi Penilaian Dari Permainan

Dari grafik pada Gambar 8 untuk pertanyaan 1 memiliki jawaban yang beragam, secara garis besar pemain mengatakan permainan cukup bagus $82 \%$. Pertanyaan nomor 2 dengan jawaban $90 \%$ menyatakan bahwa permainan merupakan permainan pembelajaran. Pertanyaan nomor 3 dengan jawaban 90\% mengatakan responden sangat senang belajar dengan bermain game dari hal tersebut dapat diartikan game. Hal tersebut dapat diartikan game pembelajaran ini sangat efektif untuk pembelajaran.

\section{SIMPULAN}

Beberapa hal yang dapat disimpulkan dari hasil desain, implementasi dan pengujian dari penelitian ini adalah sebagai berikut:

1. Hasil desain game petualangan $R P G$ dengan proses pembelajaran bahasa inggris :

a. Model permainan terdiri atas permainan petualangan $R P G$ dengan model permainan Role Playing Games (RPG) dengan model pembelajaran Quest Driven Learning $(Q D L)$ telah berhasil diimplementasikan.

b. Model permainan terdiri atas permainan petualangan RPG Bima Sang Petualangan dengan model permainan Game Content Model (GCM) dengan mekanisme Role-Playing telah berhasil diimplementasikan dengan memenuhi 10 kriteria di dalam GCM. 
2. Hasil analisa menyatakan bahwa :

1. Didapatkan hasil model permainan cukup dengan nilai $82 \%$.

2. Didapatkan hasil permainan merupakan permainan pembelajaran dengan nilai $90 \%$. Responden sangat senang belajar dengan bermain game dengan nilai $90 \%$.

\section{SARAN}

B. Saran dari peneliti untuk pengembangan selanjutnya adalah Dari sisi permainan

1. Dari sisi model base, perlunya pengembangan metode lain di teknik GCM yaitu penggunaan teknik GTM (Game Technology Model) dan GSM (Game Software Model)

2. Secara teknis permainan berdasarkan pada permainan yang berbasis RPG, dimana permainan berkendara hanya sebatas penggunaan kendaraan. perlu dikembangkan lagi menjadi bentuk permainan konsol simulasi untuk mempelajari secara aplikatif fungsi dari kendaraan secara nyata (penggunaan kecepatan, gear, kopling dan drive view).

Dari sisi aplikatif

Perlu dikembangkan dengan mengintegrasikan dengan sistem server berbasis online agar bisa menjadi aplikasi MMORPG.

\section{DAFTAR PUSTAKA}

[1] A. Järvinen. 2009. Game Design for Social Networks: Interaction Design for Playful Dispositions, ACM SIGGRAPH Symposium on Video Games, pp. 95-102.

[2] Chen-Shu Wang, Yu-Chieh Li,Chia-Chen Liu. 2010. A Game-based Learning Content Design Framework for the Elementary School Children Education, IEEE Journal.

[3] D. Burgos, C. Tattersall, and R. Koper. 2007. Re-purposing existing generic games and simulations for e-learning, Computers in Human Behavior, 23(6), pp. 2656-2667.

[4] Djamarah. 2002 .Teori Motivasi, edisi 2 (ed-2), Jakarta : PT. Bumi Aksara

[5] Johan Den Haan. 2009. MDE - Model Driven Engineering - reference guide, http://www.theenterprisearchitect.eu/blog/2009/01/15/mde-model-driven-engineeringreference-guide/,Diakses tanggal 31 Maret 2017.

[6] Jui-Hung Chen, Timothy K. Shih, Jui-Yi Chen. 2012. To Develop the ubiquitous Adventure RPG (RolePlay Game) Game-Based Learning System, IEEE Journal.

[7] Jung-Ying Wang, Yong-Bin Lin. 2010. An Effective Method of Pathfinding in a Car Racing Game, IEEE Journal.

[8] M. Prensky. 2003. Digital game-based learning, ACM Computers in Entertainment, 1(1), pp. 14.

[9] Stephen Tang and Martin Hanneghan. 2010. A Model-Driven Framework to Support Development of Serious Games for Game-based Learning, IEEE Journal. 
[10] Stephen Tang, Martin Hanneghan and Christopher Carter. 2013. A Platform Independent Game Technology Model for Model Driven Serious Games Development, Academic Publishing International Ltd.

[11] Zaqiu Rahman. 2015. Program Bela Negara Sebagai Perwujudan Hak Dan Kewajiban Warga Negara Dalam Penyelenggaraan Pertahanan Negara, RechtsVinding Online 